Teaching the Core Values of Caring Leadership

By: Judy B. McDowell, Randy L. Williams, Donald D. Kautz

McDowell, J.B., Williams, R.L. II, Kautz, D.D. (2013). Teaching the core values of caring

leadership. International Journal for Human Caring, 17(4), 43-51.

Made available courtesy of the International Journal for Human Caring, Inc:

http://iafhc.wildapricot.org/page-18066

***(C) International Journal for Human Caring, Inc. Reprinted with permission. No further reproduction is authorized without written permission from the International Journal for Human Caring, Inc. ***

***Note: Full text of article below 


\title{
Teaching the Core Values of Caring Leadership
}

Judy B. McDowell, RN, MSN, CCRN

Wake Forest Baptist Health

\author{
Randy L. Williams, II, RN, MSN, MBA \\ Administrative Services Director, Kaiser Permanente South Sacramento Service Area
}

Donald D. Kautz, RN, PhD, CRRN, CNE

University of North Carolina at Greensboro

\begin{abstract}
;
Abstract

This article describes how the authors have taught the core values of the McDowellWilliams Caring Leadership Model to hundreds of nursing leadership staff at Wake Forest Baptist Health using one-page summaries. The model brings together the caring theory of Watson (2008) and the leadership theory of Kouzes and Posner (2012). The summaries stimulate discussion and provide opportunities for leaders to reflect on their own leadership within a caring framework, as well as to help light the fire within their staff as is illustrated by the exemplars of each of the core values that are included in this article.
\end{abstract}

Keywords: caritas nursing, caring leadership model, servant leadership, Watson's caring theory, Kouzes and Posner's leadership theory, five practices of exemplary leadership, teaching leadership, front-line managers

\section{Introduction}

Developing and nurturing our leaders is something that we do not always do very well in nursing, or healthcare, or in many other professions (Williams, McDowell, \& Kautz, 2011). We often fall short in selecting new leaders, orienting them properly, teaching them the core values of leadership, and mentoring them. Frequently, we choose people as leaders who have excelled in a particular task or portion of the organization's work. What we often do not consider is their capacity to lead. Do they have the ability to interact with others in a way that inspires and engages? Is there evidence that their guidance helps others to flourish? We believe teaching and role modeling the principles of caring, blended with the core values of leadership, can change the culture of an organization. When the senior leaders and managers have a common set of values and address each issue from this perspective, then the leaders stop moving from one fire to the next. Baker and O'Malley (2008) and others point out that when leaders demonstrate these skills, people become invested in the success of the organization as well as their own. In turn, happier and healthier work environments are created that generate innovation and better outcomes, which, ultimately, are fiscally sound and socially responsible.

There are myriad challenges to developing effective leaders within the healthcare industry. When we began working in this field, we came to see that teaching and role modeling the principles of caring, and the principles of leadership in a caring leadership model, could change the culture of an organization (Williams, McDowell, \& Kautz, 2011). We recognized that there were already numerous models and theories that discussed how leaders should practice in a healthcare environment. But we believed strongly that there was a need for a model that integrated leadership and caring, since in healthcare we are affecting people's lives every day and at very vulnerable times. The model we envisioned addressed our leadership responsibilities and was aligned with our motivation to work in an industry that is critical to the health and well-being of our communities. The result is the caring leadership model (Williams, McDowell, \& Kautz, 2011), which is grounded in the theories and underlying core values of Watson (2008) and Kouzes and Posner (2012). The authors have taught the caring leadership model to nurse leaders in 50 patient care areas at Wake Forest Baptist Health (WFBH), a Level 1 trauma and academic medical center with 872 licensed beds and the first Magnet ${ }^{(}$designated hospital in the Carolinas, and in Lexington Memorial, a community-based Wake Forest Baptist Health hospital with 94 licensed beds. Our goal is to have servant leadership (Drucker, 2006) come alive for these aspiring leaders.

The caring leadership model is based on Watson's (2008) caring science. This approach involves being heart-centered and authentically present, in the moment, in the work we do, which ultimately is a process of being and becoming. Watson's theory of human caring - preserving humanity and human dignity - has evolved into a philosophy with 10 caritas processes that address the essence of caring and provide practitioners a solid foundation of values upon which to carry out their work (Caritas, from the Latin, means to cherish, appreciate.) Table 1 includes the brief descriptions we have provided staff at WFBH to assist them to implement the 10 caritas processes in their daily practice. Caritas practitioners function from a caring 


\section{Table 1}

\section{WFBH's Conceptualization of Watson's 10 Caritas Processes}

1. Practice of loving-kindness and equanimity within the context of caring consciousness. Take a breath and ask, "Why am I here?" Pause in chaos, go back to your core values and repattern yourself.

2. Being authentically present and sustaining the deep belief system and subjective life world of self and one-being-cared for. Be present in the moment. Be mindful of what you are doing and do it with the intention to care. Your very presence may be the difference between hope and despair.

3. Cultivation of one's own spiritual practices and transpersonal self, going beyond the ego self. Become more self-aware. Honor and offer loving-kindness to self; even those aspects we fear or dislike. Commitment to caring-healing requires focusing on our personal/professional growth.

4. Developing and sustaining a helping-trusting, authentic caring relationship. Building caring relationships requires deepening our humanity; being compassionate, aware, and awake to others' dilemmas.

5. Being present to and supportive of the expression of positive and negative feelings as a connection with deeper spirit of self and the one being cared for. Choose how to be in relationships and encounters with others. We have a responsibility to transform patterns of toxicity in our organization.

6. Creative use of self and all ways of knowing as part of the caring process, to engage in the artistry of caring-healing practices. Caring involves all ways of knowing, including understanding, insight, reflection, and wisdom.

7. Engage in genuine teaching-learning experiences that attend to unity of being and meaning attempting to stay within other's frame of reference. Learning involves a meaningful and trusting relationship, honoring the whole person.

8. Creating healing environment at all levels, physical as well as non-physical, subtle environment of energy and consciousness, whereby wholeness, beauty, comfort, dignity, and peace are potentiated.

9. Assisting with basic needs, with an intentional caring consciousness, administering "human care essentials," which potentiate alignment of mind-body-spirit, wholeness, and unity of being in all aspects of care. When touching another body, we are also touching the mind, the heart, and the soul. Meeting the basic needs of the body is a sacred act.

10. Opening and attending to spiritual, mysterious, and existential dimensions of one's own life and death; soul care for self and onebeing-cared for. Be open to mysteries. Recognize we do not have all the answers. Allow for miracles.

consciousness that permeates their souls and can be felt by the recipient.

Kouzes and Posner's (2012) work in the leadership realm is based on the belief that leadership is, above all, a relationship that is values-based with a foundation of credibility. Their five practices of exemplary leadership model is easy to understand, appropriate for use in any environment, easy to remember, and practical and realistic, which is why they have recently published the fifth edition of their book. A brief description of how we have implemented Kouzes and Posner's (2012) five practices at WFBH is presented in Table 2. The message is that mastery of leadership requires mastery of skills central to developing and maintaining positive relationships with others; further, the authors specifically address the challenges leaders have in encouraging the heart.
The caring leadership model (Williams, McDowell, \& Kautz, 2011) provides a way to encourage the heart and brings together the core values of a caring leader. It marries the most widely recognized caring and leadership theories to create a solid basis for the growth and development of leaders. Integrating the five practices of exemplary leadership with the 10 caritas processes, the caring leadership model identifies five core values that are essential to success for any leader in today's healthcare environment especially if success is defined by how a leader cultivates and enriches the human condition:

- Always lead with kindness, compassion, and equanimity.

- Generate hope and faith through co-creation.

- Actively innovate with insight, reflection, and wisdom.
- Purposely create protected space founded upon mutual respect and caring.

- Embody an environment of caringhelping-trusting for self and others.

We have developed and implemented a leadership development program using the caring leadership model. Kouzes and Posner have recognized our work by featuring our work on their website. While the model is appropriate for developing leadership capacity in anyone, in any profession or circumstances, we have initially focused on working with aspiring nurse leaders. Our goal is to help front-line leaders light the fire within their staff, rather than focusing on lighting a fire under the staff.

The foundation for this model of care was the hospitals' shared decision-making structure (McDowell et al., 2010), which empowers every direct care nurse to have a 
Teaching the Core Values of Caring Leadership

Table 2

Implementation of Kouzes and Posner's Five Practices at WFUBMC

1. Model the way. Nurse leaders at WFUBMC share their positive experiences and discuss ideas of how to make them occur more frequently. They also identify barriers and brainstorm for strategies to help with those opportunities.

2. Inspire a shared vision. We explore together what it means to be a caring leader in our eyes and our peers. We also explore the impact that our core values have on our day-to-day leadership.

3. Challenge the process. There is an increased emphasis on decisions and their impact on a caring-healing environment for all. We acknowledge that caring as a leader is necessary if a culture of caring is desired in the organization.

4. Enable others to act. The model has wide appeal among the leaders to assist in developing a caring consciousness and leadership skills to bridge the gap between the old way of management to a purposeful acknowledgement of the importance of caring at all levels and in all actions.

5. Encourage the heart. Leaders at multiple levels appreciate the purposeful exploration of what it means to be a caring leader and the time taken to make this way of being not just an expectation, but an imperative.

voice in decisions that affect their practice. Leaders who practice shared decisionmaking have extraordinary responsibility to ensure that the proper level of authority is given in the right situation such that accountability for the decision being may rest with the appropriate party. As a result, they also must have educational opportunities and mentoring to develop and enhance their leadership skills. The leadership theory of Kouzes and Posner (2012) guided this process.

The teaching/learning strategies that we use in our classes to illustrate the core values and engage the nurse leaders in integrating them into their practice include one-page summaries of core value concepts with reflection and discussion, which we have included in this article. In order to stimulate reflection, we share exemplars from previous classes to demonstrate meaning of each core value, and then participants then write their own lived examples for each of the core values. Participants are divided into groups and complete worksheets with discussion questions to make sure the concepts are real and applicable in their day-to-day work. Groups present their conclusions in class for general discussion and reflection upon topics presented. At the end of the course, participants in small groups complete a capstone project that demonstrates how they are incorporating the core values into their own specific practice environment. Their projects have been amazing! They all have a core power point which is complemented by their presentation of skits, games, music, art, and/or videos. Their presentations are highlighted in a day of celebration with their leaders and peers.

When teaching participants, we have found that the use of one-page summaries of each of the core values help staff and managers to see how the core values are reflected in their work and encourage them to address all issues from these core values, rather than moving from one fire to the next. The content we use in each of these summaries is briefly summarized in the following paragraphs. We purposely cite well-known authors of leadership books to show that these core values are universal and well received as values that are important to success. In addition, in the training classes, participants write exemplars to illustrate the core values, and we have included one of these exemplars to illustrate each of the core values. Each one-page summary speaks in generalities about leadership so that participants can internalize this core value and show how they can apply the value in their own work setting. The goal of each of these one-page summaries is to have servant leadership come alive for these aspiring leaders. The classes, work sessions, and onepage summaries have been very effective methods of teaching with our leaders. See
Box 1, illustrating how Suzanne Pert, RN, BSN, the Assistant Nurse Manager of our Palliative Care Unit implemented the core values on her unit on Januafy 15, 2013.

Always Lead with Kindness, Compassion, and Equanimity

When teaching the core value of Always Lead with Kindness, Compassion, and Equanimity, we provide the participants with the following summary on a one-page handout:

Is there really room for kindness and equanimity in the workplace?

Healthcare today is a big business with ever-changing demands and constant drives to increase efficiency. In this environment, is it really going to make any difference if we practice lovingkindness? Who has time for this? Is equanimity really possible? Kindness can be a very simple act of pausing to listen to another's story, genuinely appreciating persons as they enter your space, and practicing empathy.

Research in neuroscience and social sciences has revealed the physiological and cultural basis of emotional resonance in social networks and its effects on both individual and group performance (Watson, 2008). If we agree that healthcare is the business of caring for the human condition, and if we make the assumption that humans are more than machines, then we must 
Box 1

Suzanne Pert's email and narrative "Stop and Listen" illustrating her core values of caring leadership

Hi Judy!

I was a part of the Caring leadership back this summer and enjoyed it so much. This morning, I thought about the poems, letters and inspirational sayings that you would share. I wrote this, this morning after seeing one of my nurses at the bedside. I felt so moved by what I saw that I placed this on stationery, laminated it, and read it aloud for her at the nurses' station. I wanted to share with you and thought that maybe somewhere along the way; you may want to share as well. Thanks again!!! Suzanne Pert, RN, BSN, Assistant Nurse Manager, Palliative Care Unit, Wake Forest Baptist Health

Stop and Listen

This morning I chose to come into work earlier than I usually do so that I could spend some time with staff members that I do not get to see as often. It was still dark outside and misting rain. I entered the unit that was quiet and peaceful. Our six patients that are here were tucked away comfortably in their beds. Some had family present to hold their tired hands and some did not.

I smiled at the unit secretary and said "good morning." She pleasantly returned with the same. I sat at the nurses' station to pull up the census list as I do each day, and a soft voice caught my attention. I heard someone singing. I looked around but saw no one. I continued doing what I had sat down to do and heard the voice again. This time I looked at the secretary in mystery who pointed to bed 06 which was near the nurses' station. I quietly got up and walked towards the door. I leaned against the frame only to see a silhouette of a nurse whose reflection was gleaming off of the window overlooking the city. Behind her, I could also partially see three steeples from nearby churches. The raindrops from outside were slowly rolling down the glass. The lighting in the room was dim, and the warmth was easily embraced. I could see the nurse gently rubbing the patients arm as she sang beautiful hymns that touched my spirit. Her love and compassion were so apparent even though I could only see the outline of her in the dark window.

At that very moment, I became tearful as I was quickly reminded why we do what we do. This particular patient did not have someone to hold their hand, or stroke their arm. This particular patient did not have someone to tell them that everything was going to be ok. Instead her nurse stepped in and took on this responsibility through love and compassion. At this very moment, I witnessed nursing at its finest. I was able to see how caring for a dying patient can be beautiful. What a gift - to be able to embrace and provide comfort when it is needed most.

There are times that our responsibilities keep us from truly stopping and spending quality time with others like we would like to do. We all become busy, and one task is replaced by another. It is often forgotten during such hectic times to stop, but today she did......

Suzanne Pert, RN, BSN, January 15, 2013

recognize the relationships of their emotions to optimal wellness, and the ways in which emotional resonance affects performance.

Baker and O'Malley (2008) in The Power of Kindness suggest that leaders have always relied on emotions to motivate others: Great managers inspire employees to collaborate when problem solving, coaches rally players to win, and politicians persuade others to vote for them by appealing to their emotions. Baker and O'Malley interviewed many leaders and found that the combination of leadership and kindness are complementary and gives leaders an edge. So how does a leader function with equanimity or balance? How do we promote and accept positive and negative feelings? How do we authentically listen to another's story?

Leaders must first strive for balance in themselves and then in how they work with their employees. This can be accomplished through reflecting on what you find meaningful in your work, determining how you define success for yourself, and taking the time to consider your personal definition of success in relation to your organization. This time of reflection and personal mission building helps to define what success means for you and will help you to find balance and the motivation to function optimally in the workplace. Helping employees find that balance requires openness to their thoughts and feelings which may differ dramatically from yours.

Rita Louise, $\mathrm{PhD}$, an alternative health and healing practitioner, and author of The Power Within and other books states, "When we give ourselves permission to express all our feelings (both positive and negative ones), and when we allow them to run their course, we always feel lighter, fresher, and more centered. When our emotions are balanced, we can experience all of them to their fullest. It is easier for us to own them and then process them quickly and effortlessly. They are allowed to flow through us. We breathe them in, we experience them, and we let them go. It is the beauty of our existence" (Louise, 2012). 
As Glen Hubbard, Dean of Columbia Business School, points out in the preface to Baker and O'Malley's (2008) book, Leading with Kindness, "The ability to leverage one's kindness is not a soft skill. On the contrary, it is a no-nonsense approach to business that can return hard dividends in organizational effectiveness and business performance. For the beginner, leading with kindness is a good first lesson. For the seasoned leader, it is a gentle and often entertaining reminder that there is no time like the present for mastering kindness" (p. xi).

After reading this summary, and participating in the class session, one of the nurses wrote the following exemplar to illustrate how she sees this core value in her practice. Note how clearly she is able to picture what kindness, compassion, and equanimity all look like in her practice:

\section{Exemplar of Always Lead with Kindness,} Compassion, and Equanimity I admitted a patient to our medical unit last week who had been transferred from another hospital. He and his wife were very upset about how he had been treated. They had a lot of anger over the care he had received and the lack of real caring they had both felt. I knew that it was important to allow them to express those feelings and help them to get past them. After a while, I was able to get them to express the positives of how they wished his care would be. We talked about goals that we could sit together to make this happen. Both the patient and his wife felt much better... less frightened and more comfortable that we cared about him as a person and would try to meet his needs with kindness and he would be treated with dignity and respect.

\section{Generate Hope and Faith through Co-creation}

The second core value of our leadership model is Generate Hope and Faith through Co-creation. In teaching nurses about this core value, we chose to focus on Goertz's (2011) work on healing presence as the essence of nursing. Our goal in choosing this wonderful source was to expose our nurses to Goertz's work in hopes that they will get her book and share it with staff on their units. We believe that this is one way that we can teach our leaders to transform nursing. We include the following information on a one-page handout for the nurses:

Do we really take the time to be sure that we are generating faith and hope in our work with our patients and families? Do we even recognize when faith and hope are needed? Do we identify these as needs for ourselves as well as our colleagues?

Do we inspire our patients and families as we care for them in their times of deepest need? Do they feel our faith and hope as we struggle to address their problems and concerns? Are we able to co-create an environment to keep hope and faith alive? Do we share this vision with our colleagues?

We must respect the authenticity that is required of us for presence in situations calling for faith and hope. We must also recognize and honor the meaning and substance of the lives of those for whom we care.

Research has shown that when people are facing crises of illness, pain, loss, stress, despair, grief, trauma, and death...they "go home" to their culture and their inner deep belief systems. That is when they need us most...to accept them where they are.... and to address the concerns of their hearts and support them in "what matters most" at the time (Watson, 2008).

Watson's Caritas Process One, loving kindness and equanimity, is the foundation for co-creating an environment of love, faith, and hope in which our patients and families can thrive, even in the most difficult of times. Also, it is only through our own authentic presence that we are able to connect to others and open ourselves to the possibilities of outcomes we may not have considered. This authenticity is key to how we are seen and experienced by others. We must touch their experience in a manner that is helpful and hopeful, and that is healing rather than diminishing. (Goetz, 2011).

To encourage and support our patients and families through their crises, we must use all our ways of knowing to help them find methods to sustain their faith and hope. Genuine teaching and learning experiences are interpersonal and interactive processes in which both the nurse-teacher and patientlearner are engaged in co-creation of a caring, healing environment. This core value is also essential to the development of a trusting relationship (Caritas Process Four) between the nurse and patient.

How do caring leaders use their knowledge, skills, and feelings to bring about transformative relationships and healing for self and others? Goertz (2011) says that, "Within each of us lies a deeper way of knowing and being in the world" (p. 206). Presence is our way of being that is felt by others. We must open ourselves up to create a safe and compassionate space that allows others to sort through their situation honestly, clearly, and with candor and courage.

As we work to deepen our own faith and hope, we make a powerful connection to others. The privilege of being a staff nurse or manager gives us innumerable opportunities for expansive and creative relationships that enlarge our capacities and sensibilities and inform our caritas consciousness. A caring leader lives and inspires this level of work.

This one-page handout has been a very effective teaching strategy, as is illustrated in the following exemplar written by one of the leaders of the Pediatric Intensive Care Unit (PICU):

\section{Exemplar of Generate Hope and Faith through Co-creation}

We had a 3-year-old patient in the Pediatric Intensive Care Unit (PICU) 
that had been very sick for his entire short lifetime. He had been in and out of our unit several times. At this time, he was definitely terminal and his family wanted very badly to make it possible for him to die at home. We also felt strongly that this was the right thing to do. We had a team meeting and discussed ways of making this happen. We worked diligently with the parents to teach them how to feel safe in caring for him and to find ways that we could support them in their hopes and beliefs. We taught them how to manage his medications and his respiratory treatments. I felt that we learned as much as they did as we went through all of this. We also sent one of our nurses and respiratory therapists with them to get them settled at home. Everything went much more smoothly than you would believe! He died three days later surrounded by his family and favorite things.

\section{Actively Innovate with Insight, Reflection, and Wisdom}

Our third core value is Actively Innovate with Insight, Reflection, and Wisdom. Our experience has táught us that nurse leaders rarely thought about their role as innovators. In our one-page summary, we focused primarily on teaching our nurses what innovation is, and we included a brief reference to Peter F. Drucker's (2006) model of servant leadership. Once again, we hoped that including the Drucker reference would spark our leaders' interest in seeing how nurses can use management innovators who have changed the world. We included the following general description of innovation on our one-page summary:

Innovation - who has time for that? Well, today it is not a question of having the time for innovation - it is a must if we are to survive. This is especially true in a healthcare environment as all the things around us are changing at a faster pace than ever before. Healthcare reform is no longer a question of if or when, it is happening now, and where there are still many uncertainties, what we do know is we will have to do more with less and have better outcomes. More than ever, the public is asking for healthcare to be personalized and for us to meet individuals where they are - physically, mentally, and emotionally. Nowadays, the only constant in our lives and in our work is change. Yet, while this may be our reality, it is not necessarily an ideal way to function.

Our values, particularly our leadership values, must be defined and refined such that when the winds of change come, we are grounded by remembering what matters most to us. In the context of the caring leadership model, "Actively innovate with insight, reflection, and wisdom," is key to surviving and thriving.

Innovation is often born out of necessity, which provides opportunities to bring together our collective ways of knowing in order to make things better for our future, Innovation derives from the Latin word innovatus, from the verb innovare "to renew or change." The term innovation refers to the creation of better or more effective products, processes, technologies, or ideas.

Peter F. Drucker, considered by many to be the most influential management thinker who has ever lived, points out (2006) the usual reasons for innovations are changes in industry structure, market structure, local and global demographics, human perceptions, and mood and meaning. In the current society of healthcare, innovation is critical. This requires insight, wisdom, and reflection in order to ensure that innovations are meaningful, practical, and valuable.

This core value of caring leadership requires that we use our knowledge and collective wisdom. We must combine intuitive knowledge from experience with the purposeful use of reflection to design innovative processes, ideas, and practices that produce more valuable outcomes.

Does this occur in isolation? In the real world, rarely does one individual have all the knowledge required for an innovative process to arise in a way that is practical and sustainable. However, when a leader practices this core value, it promotes environments where teams are brought together to dream and design new ways of being to embrace the storms of change and at the same time, hold true to their values.

We believe the following exemplar illustrates the core value of innovation. When we dream, we dream that what the nurse leader describes is a common practice in every healthcare institution yet we know it is a rarity. Once again, we believe that teaching nurses this core value helps them to believe that they have both the permission and duty to ensure these opportunities occur for our patients and those they love.

\section{Exemplar of Actively Innovate with Insight, Reflection and Wisdom} Our patient had been in the intensive care unit for almost two weeks. His condition was slowly deteriorating and his fiancé spent most of the time at his bedside. They had been living together for many years but had never married. It was their wish to be married before he died. They knew he would never be able to go home... his care was much too complex. There were multiple reasons why the couple desired this marriage including financial implications and religious beliefs. We really had to "challenge the process" since ICUs were not wedding-friendly places. All of our staff used their creativity - whether it was to form an archway with tulle and greenery - to put together wedding attire - bring in refreshments for the reception - to work with the family members to set the right time and bring in the chaplain - to have someone to take pictures, the bridesmaids (nursing staff) needed gowns, and more than anything, to make sure their cultural and religious beliefs were upheld. The wedding was beautiful, yellow isolation gowns for 
the bridesmaids! And there was not a dry eye in the room. We really felt we had given them the greatest gift that we ever could have - and what they wanted most - the opportunity to become husband and wife!

\section{Purposely Create Protected Space Founded upon Mutual Respect and Caring}

Our fourth core value is Purposely Create Protected Space Founded upon Mutual Réspect and Caring. The following is the content we include in our one-page summary. We have found in teaching our nurses that this is a very complex topic to think about. We know how to create safe units that promote healing, but what exactly is a protected space? When reading these general statements, what comes to your mind about creating protected space?

Protected space-What is it? How do you create it? Is there any such thing or should there be? The environment in which we provide care for our patients and families is the most important culture medium there is. That environment should provide the nutrients required for growth and development of both the human and the being.

We must intentionally work together to create a culture that will promote growth and encourage loving-kindness as well as faith and hope. A caring and healing environment is one in which people feel safe, cared for, and cared about. It is a place where people feel enabled to act and are comfortable taking actions that could be risky and daring.

This culture provides a place where it is okay to be vulnerable and exposed. This is a place where you can feel secure enough to open yourself up to scrutiny, knowing you are surrounded by a community supporting you with an intentional caring consciousness.

When patients come to us for care, they may be at the most vulnerable times of their lives. Our covenant requires us to honor and respect the sacredness of our time with them and know that for them to allow us such private access to their bodies and their souls is intimidatingly momentous.

When we connect with them, we must do so at the most basic and fundamental level. We must meet them where they are in their understanding and in the meaning of their experience at this particular time. We must identify their basic needs, physical, emotional, psychological, and spiritual, and establish a covenant with them to provide whatever is required for their safety and well-being.

We must also create the same kind of environment for our colleagues and for ourselves. We cannot really separate ourselves from others. What we do for ourselves must extend to others. In return, what we do for others must extend to ourselves. We are all part of the same humanity, with the same needs for wholeness. We all have an inherent desire to flourish. With the appropriate culture medium, we will all not only survive but thrive and walk forward with excitement and anticipation into a bright and fulfilling future.

In conclusion, we must establish a protected space that is mutually agreed upon, with loving-kindness and respect as the guiding parameters. This is a space where all are enriched and empowered to become something more than themselves and to contribute to a world that is more than we ever thought possible.

One of our managers illustrates how she and the staff on her unit created a protected space on their unit in the following exemplar:

\section{Exemplar of Purposely Create Protected Space Founded upon Mutual Respect and Caring "Sarah" was a 90-year-old patient that was on our older adult unit. We had all become very fond of her and when her condition began to deteriorate, she was scheduled to be moved to our hospice/ palliative care unit. We had gotten to know her three daughters very well during her stay with us and we knew their frailties as well as hers. They were}

such a loving family. We did not feel good about moving her when her death seemed to be so close at hand. We talked to our manager about keeping Sarah on our unit a bit longer...in her room that she was settled in. We had encouraged her family to bring in pictures of her children and grandchildren.... and they had brought in one of her favorite quilts that she had made when she was younger and always kept on her bed. We put a CD player by her bedside to play some of the gospel songs that she loved so well. We also helped her sisters when they wanted to assist with her daily care... they loved to brush and braid her long hair and put on her rose-scented lotion. Sarah did not live but one more day... but for those 24 hours she was made to feel at home in her room.

\section{Embody an Environment of Caring-} Helping-Trusting for Self and Others

A caring-helping-trusting environment what is it and how do we create it? And why? While our fourth core value of caring leadership speaks to the concept of protected space and the necessity to create that space for our patients and families as well as ourselves, the fifth and final core value takes that concept a step further...it is what we do with that space that is most important. The following content is what we include in our one-page handout on this core value.

How we make that space into a caringhelping-trusting environment depends on us. It is about what we and our colleagues bring into that space that makes the difference. It is about how we interact with others, how we are being when we are doing.

When we enter the space of another, we bring all of our knowledge, skills, experience, beliefs, hopes, and dreams. The same is true of the other person. It is the interaction between the two that has transpersonal dimensions. The experience is an opportunity for two people to come together and find common ground to work toward bringing healing to that space. 
Caring-helping-trusting is manifest in healing for both.

Embodiment signifies personification of the healing environment. We are an integral part of the environment and will have a critical impact on outcomes for our patients as well as for ourselves. Creating healing environments is as important in caring for self as in caring for others, and we must do so with a conscious intention to heal.

Cultivating these caring-helping-trusting relationships with self and others is an integral part of caring leadership and is vital in encouraging the heart of those for whom we are caring as well as for those whom we are privileged to lead.

Within this protected space, caring relationships can flourish with authentic human connection and responses and can lead to healing for all involved. First we create the protected space, then we embody the crucial characteristics of caring-helpingtrusting, and as relationships develop within a caritas consciousness framework, the caring moment evolves into a healing experience.

Relationships are the fundamental core of the embodied caritas environment. Caring relationships and skills must be cultivated and practiced. It is within these hallowed moments that true healing occurs for us and our humanity. It is here that we find peace and equanimity for our world.

In the following exemplar, the nurse not only shows how this core value is implemented on her unit, but wrote about her own family, as one of them became the patient in our facility. We believe this is the highest compliment that our nursing leaders can pay our staff, by allowing them to care for our own families, and then rejoicing in the care that they receive.

\section{Exemplar of Embody an Environment of Caring-Helping-Trusting for Self and Others}

My brother-in-law had been a patient on the cardiac floor of the hospital for several days. He was in end-stage heart failure. All of the nurses had been wonderful in caring for him, and he had felt well cared for. Eventually he was sent to a nursing home. A couple of days later, he began to get in to acute distress and was sent by ambulance to the hospital emergency room. He arrived there late in the day on a very busy and crowded night shift. My sister was not well herself and was terrified as they brought him back into the emergency department (ED). When the nurse who had been assigned to him came over, it turned out to be one of the nurses who had cared for him previously on the cardiac floor. At that instant, the world changed for both him and my sister. This nurse immediately recognized him and started talking to him about things she knew mattered most to him, his wife, and his art. Her knowledge of the person he was completely made her care of him personal. He already thought of her as an excellent nurse, and he felt an immediate connection to her. She truly embodied that caring environment to both him and my sister. They felt that she made a scary situation less fearful and safe.

\section{Conclusion}

We believe that a loss of trust and confidence in our leaders and organizations is at the root of the workforce issues we face today. Where these challenges have existed, we have seen the caring leadership model and our educational programs which teach the model to our leaders play an important role in developing leaders who are eager to engage with staff and colleagues and adept at creating space for authenticity and mutual respect. In our classes, we have seen how teaching the core values of the caring leadership model helps aspiring leaders see how to light the fire within their staff. We believe it is possible to create environments that allow leaders to live agreed-upon values and encourage and promote flourishing of the human spirit in the workplace. Ultimately, we hope this creates not only an immediate positive benefit but a culture shift that may produce exceptional results that are sustainable. We are proud of what we have accomplished at WFBH in our leadership classes. We hope we have inspired you to focus on these core values when developing leaders in your workplace.

\section{References}

Baker, W. F., \& O’Malley, M. (2008). Leading with kindness: How good people consistently get superior results. New York, NY: AMACOM Books.

Drucker, P. F. (2006). Innovation and entrepreneurship. New York, NY: HarperBusiness.

Goertz, J. (2011). Healing presence: The essence of nursing (2nd ed.). New York, NY: Springer.

Kouzes, J. M., \& Posner, B. Z. (2012). The leadership challenge: How to make extraordinary things happen in organizations (5th ed.). San Francisco, CA: Jossey-Bass.

Louise, R. (2012). Attaining emotional balance. Inner Self. Retrieved from http://www.interself.com/Behavior_ Modification/attaining_emotional_ balance.htm.

McDowell, J. B., Williams, R. L., Kautz, D. D., Madden, P., Helig, A., \& Thompson, A. (2010). Shared governance: 10 years later. Nursing Management, 41(7), 32-37.

Watson, J. (2008). Nursing: The philosophy and science of caring (Rev. ed.). Boulder, CO: University Press of Colorado.

Williams, R. L., McDowell, J. B., \& Kautz, D. D. (2011). A caring leadership model for nursing's future. International Journal for Human Caring, 13(1), 31-35. 


\begin{tabular}{|c|c|c|}
\hline \multicolumn{3}{|c|}{$\begin{array}{c}\text { Model of Care } \\
\text { Patient/Family, Team, Self, Community }\end{array}$} \\
\hline \multicolumn{3}{|c|}{$\begin{array}{l}\text { McDowell-Williams } \\
\text { Core Values of Caring Leadership }\end{array}$} \\
\hline I & $\begin{array}{r}\text { Always lead with kir } \\
\text { Generate hope } \\
\text { Actively innovate } \mathrm{k} \\
\text { osely create protected } \mathrm{sp} \\
\text { abody an environment of }\end{array}$ & $\begin{array}{l}\text { ess, compassion, and equanimity } \\
\text { d faith through co-creation } \\
\text { insight, reflection, and wisdom } \\
\text { founded upon mutual respect and caring } \\
\text { ring-helping-trusting for self and others }\end{array}$ \\
\hline \multicolumn{3}{|c|}{ Shared Decision-Making } \\
\hline \multicolumn{3}{|c|}{$\begin{array}{l}\text { Caring Leadership } \text { Model }^{\circ} \\
\text { Judy B. McDowell, RN, MSN, CCRN \& Randy L. Williams, RN, MSN, MBA }\end{array}$} \\
\hline \multicolumn{3}{|c|}{ Core Values of Caring Leadership Model Crosswalk } \\
\hline $\begin{array}{l}\text { McDowell-Williams } \\
\text { Caring Leadership Model }{ }^{\circ}\end{array}$ & $\begin{array}{l}\text { Kouzes \& Posner } \\
\text { Leadership Theory }\end{array}$ & $\begin{array}{l}\text { Jean Watson } \\
\text { Theory of Human Caring }\end{array}$ \\
\hline $\begin{array}{l}\text { Always lead with kindness, } \\
\text { compassion, and equanimity. }\end{array}$ & Model the Way & $\begin{array}{l}\text { - Practice of loving-kindness and equanimity; caring consciousness } \\
\text { - Being supportive of expression of positive and negative feelings }\end{array}$ \\
\hline $\begin{array}{l}\text { Generate hope and faith } \\
\text { through co-creation. }\end{array}$ & Inspire a Shared Vision & $\begin{array}{l}\text { - Being authentically present in the moment } \\
\text { - Engaging in genuine teaching-learning experience }\end{array}$ \\
\hline $\begin{array}{l}\text { Actively innovate with insight, } \\
\text { reflection, and wisdom. }\end{array}$ & Challenge the Process & $\begin{array}{l}\text { - Cultivation of one's own spiritual practices and transpersonal self } \\
\text { - Creative use of self and all ways of knowing }\end{array}$ \\
\hline $\begin{array}{l}\text { Purposely create protected } \\
\text { space founded upon mutual } \\
\text { respect and caring. }\end{array}$ & Enable Others to Act & $\begin{array}{l}\text { - Creating healing environments at all levels } \\
\text { - Assisting with basic needs, with an intentional caring } \\
\text { consciousness }\end{array}$ \\
\hline $\begin{array}{l}\text { Embody an environment of } \\
\text { caring-helping-trusting for self } \\
\text { and others }\end{array}$ & Encourage the Heart & $\begin{array}{l}\text { - Developing and sustaining a helping-trusting authentic caring } \\
\text { relationship } \\
\text { - Soul care for self and the one being cared for }\end{array}$ \\
\hline
\end{tabular}

Figure 1: Caring Leadership Model ${ }^{\circ}$

Reference: Williams, R.L., McDowell, J. B., \& Kautz, D. E. (2011). A Caring Leadership Model for nursing's future. International Journal for Human Caring, 15(1), 31-35.

\section{Author Note}

Judy B. McDowell, RN, MSN, CCRN is Professional Practice Manager, Wake Forest Baptist Health, Winston-Salem, North Carolina; Randy L. Williams, II, RN, MSN, MBA, is Administrative Services Director and Interim Clinical Adult Services Director, Kaiser Permanente South Sacramento Service Area, Sacramento, California, Associate Faculty, Watson Caring Science Institute, Boulder, Colorado; and Donald D. Kautz, RN, PhD, CRRN, CNE, is Associate Professor of Nursing, The University of North Carolina at Greensboro, North Carolina. Correspondence concerning this article should be addressed to Judy McDowell at jbmcdowe@wakehealth.edu or to Randy Williams at Randy.L.Williams@kp.org

The authors gratefully acknowledge: Mrs. Maureen E. Sintich, MSN, MBA, RN, WHNP-NC, NEA-BC, Vice President Operations, Chief Nursing Officer, Wake Forest Baptist Health for her leadership, vision, and mentorship; the wonderful editorial assistance of Ms. Elizabeth Tornquist, MA, FAAN; and the wonderful assistance of Mrs. Dawn Wyrick with this manuscript. 